\title{
Hardwood forest inventory of Dra-Naga Arboretum (Djebel El Ouahch, Constantine, Algeria)
}

\author{
${ }^{1}$ Rached-Kanouni Malika, ${ }^{2}$ Belhiouani Hadjer, and ${ }^{3}$ Hadef Azzedine
}

\begin{abstract}
Managed by the Conservation of Forests (Constantine), the arboretum of Draa Naga which is primarily for forestry covers an area of 30 hectares. This area consists of 77 plots where 31 are plots of hardwoods. The current ecological status of the arboretum is poorly understood. After a decision by Conservation of Forests for the protection and restoration of the arboretum, the precise knowledge of existing forest resources and their evolution has become indispensable.

The objective of our study is to collect data on the current environmental status of the site and timber resources in order to establish a reference state (zero state) of the arboretum. An inventory allowing full knowledge of quantitative data on these resources from dendrometric parameters collected from 7 plots of hardwood: P1, P3, P4, P8, P50, P52 and P60.

Three types of analysis are carried out: structural analysis, analysis of the principal species and statistical analysis. A total of 206 individuals belonging to 7 species and 3 families were identified. The densest plot is P1 (Quercus petraea), the largest volume of standing trees was recorded in the plot P3 (Eucalyprus ovata). The structure heights shows that trees in the height classes between 2 and $4 \mathrm{~m}$ have a very high density, evidence of natural regeneration. The total structure indicates that small trees are more abundant than large $(17.5<\mathrm{d} \leq 27.5 \mathrm{~cm})$. Indeed, this work is a database for the arboretum but it represents only one aspect to consider protecting and restoring it.
\end{abstract}

Index Terms-Arboretum, Hardwood Forest Inventory, Zero State.

\section{INTRODUCTION}

An arboretum is a garden containing a collection of documented woody plants maintained for aesthetic, educational, and scientific purposes. To have any lasting importance, an arboretum must define clearly stated purposes for itself [1]-[2]-[3]. Without stated purposes and goa1s, conflicts may develop between the aesthetic, educational, and research functions and the gardens may become cluttered with haphazard collections [4]-[5]. This inevitably destroys the appearance of the landscape that the collections originally were to enhance [6]-[7]-[8].

This study concerns particularly the arboretum of Draa Naga, created inside the forest of Djebel El Ouahch (Constantine, east-Algeria) in the fifties. Actually managed by the Forest Conservation of Constantine, it is a valuable tool for education and ecotourism. Until know, no system of measurement or supervision of its viability was created so that the ecological status is unknown at all. The objectives mainly are to collect data about the current ecological status of the site, to identify monitoring indicators to measure sustainability and, at the last, to include a system of permanent ecological monitoring in a overseeing in a proposal of a management plan for the arboretum. Monitoring is a helpful instrument when analyzing and controlling forest resources. With it, intervention can be more defined and more adapted to the reality.

Even if the studied sample was established to represent as much as possible all the species of the arboretum, some questions couldn't be answered because several mosaic of artificial forests' stand with different woods species compose the arboretum and each species has got their own particularity [9]-[10]-[11]. Permanent observation's plots could just be placed as reference (current status) but it is obvious that an integral overseeing and a pack action are necessary to preserve the viability of the arboretum. This research produces a database but it doesn't consider the entire problem. Thematic maps elaborated with Geographic Information System (GIS) give more information and make the overseeing easier [12].

\section{MATERIEL AND METHODS}

The study area of Draa Naga arboretum (Djebel El Ouahch's forest) belongs administratively to the province of Constantine (Map 1). It is located between longitude $\left(\mathrm{X}_{1}: 6^{\circ} 42^{\prime} 5^{\prime \prime}, \mathrm{X}_{2}: 6^{\circ} 42^{\prime} 30^{\prime \prime}\right)$ and latitude ( $\mathrm{Y}_{1}: 36^{\circ} 20^{\prime} 45^{\prime \prime}, \mathrm{Y}_{2}$ : $\left.36^{\circ} 22^{\prime} 15^{\prime \prime}\right)$. The estimate terrain elevation above sea level is 950 meters. The relief is characterized by a low slope (3$12 \%)$. The drainage system consists of a few ravines and collected by temporary flow regime. Its bioclimatic is semi-arid to sub-humid. The climate of the region Draa Naga is characterized by a hot and dry summer, and a cold and wet winter with an annual rainfall of $700 \mathrm{~mm}$. Soil type of forest station is silico-clay.

Research all existing documentation such as:

- Topographic Maps of the study area at $1: 25 / 000$ scale and turn them into digital format by scanning with a scanner.

- Existing thematic maps and old maps of the arboretum.

- Acquisition of a recent satellite image (2014) of the arboretum from Google Earth.

After integrating satellite imagery in the GIS, we conducted a digitalization of 77 parcels of the arboretum. Data entry field in the GIS is made by ARCGIS 10 software by creating an attribute table. This phase is assigned for each plot several fields of information such as plot number, type of existing species, the necessary work, etc... Finally, thematic maps of the arboretum are developed according to the criteria (species, Type). 


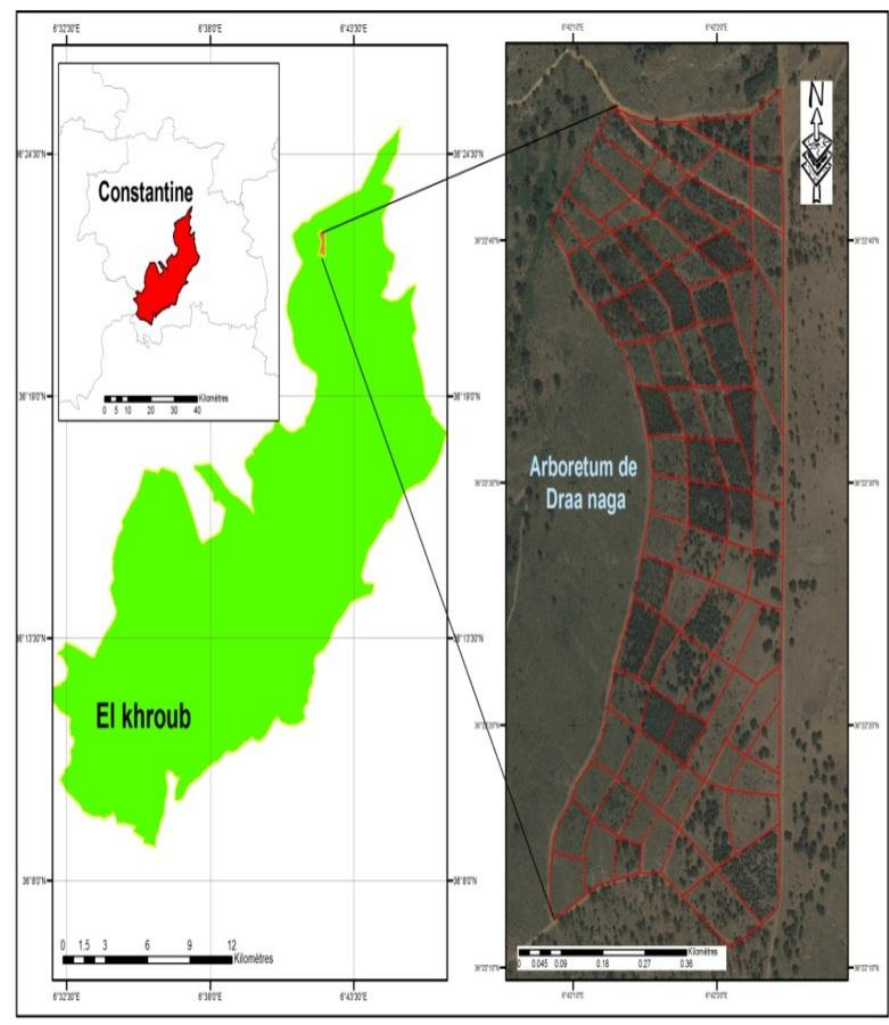

Map 1. Location of Study Area.

\section{RESULTS AND DISCUSSION}

The inventory carried out in the Draa-Naga arboretum seven plots on 30 existing hardwood has identified a total of 148 feet, or 438 feet / ha on a total area of 3.59 ha, those feet are represented by 7 forest species grouped in 4 families, the most important are: Myrtaceae, Fagaceae and Oleaceae. The year of planting each plot is between 1954 and 1960, these artificial formations are over the age of sixty.

Table 1 summarizes the different characteristics of the 7 plots studied hardwood (species, families, staff, the original plantations and years of planting).

The results show the existence of dendrometric all diameter classes (Tab. 1$)$. The rods 4 plots ( $S$. japonica), $52(F$. americana $)$ and 60 ( F. oregona) are at the stage of poles (their diameters do not exceed the $17.5 \mathrm{~cm}$ ). This means that the introduced species have not yet had time to reach large diameter.

TABLE I

Distribution OF HARdwood Stems OF 7 Per Diameter Classes.

\begin{tabular}{|c|c|c|c|c|c|c|c|}
\hline \multirow{3}{*}{ 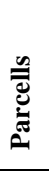 } & \multirow{3}{*}{ 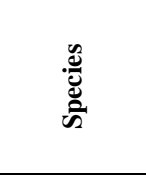 } & \multicolumn{6}{|c|}{ Diameter classes (DHP) } \\
\hline & & $\mathbf{P P}$ & $\mathbf{P E}$ & PB & $\mathbf{B M}$ & GB & TGB \\
\hline & & $\begin{array}{c}\mathrm{D} \leq \\
.5\end{array}$ & $\begin{array}{c}7.5< \\
\mathrm{d}<\end{array}$ & $\begin{array}{l}17.5 \\
<\mathrm{d}<\end{array}$ & $\begin{array}{r}27.5 \\
<\mathrm{d} \\
\end{array}$ & $\begin{array}{r}47.5 \\
<\mathrm{d} \\
\end{array}$ & $\begin{array}{l}\mathrm{D}> \\
67.5\end{array}$ \\
\hline 1 & $Q$. petraea & - & 04 & 35 & 17 & - & - \\
\hline 3 & E. ovata & - & 01 & 04 & 07 & 05 & 01 \\
\hline 4 & S. japonica & 06 & 09 & - & - & - & - \\
\hline 8 & Q. rubra & - & - & 01 & 01 & - & - \\
\hline 50 & $Q$ & - & 03 & 12 & 05 & - & - \\
\hline 52 & $F$. & 01 & 01 & - & - & - & - \\
\hline 60 & F. oregona & 07 & 05 & - & - & - & - \\
\hline
\end{tabular}

The floristic diversity expresses the distribution of species between individuals present. It is estimated for 7 plots using four parameters: the ratio of the mixture (MC),
Simpson's diversity index, diversity index ShannonWiener and Pielou evenness index (Tab. 2).

We note that the mixing coefficients range from $1 / 151$ to $1 / 5$ for the 7 plots studied hardwoods; these coefficients reflect a trend towards homogeneity of different stands. The Simpson Index is in turn equal to 0 in all plots.

TABLE II

INDICES OF FLORISTIC DIVERSITY OF 7 PLOTS STUDIED HARDWOODS.

\begin{tabular}{|c|c|c|c|c|}
\hline Parcells & MC & Ds & H' & E \\
\hline P1 & $1 / 151$ & $\mathbf{0}$ & 0.367137 & 0.217241 \\
\hline P3 & $1 / 34$ & $\mathbf{0}$ & 0.1984 & 0.117396 \\
\hline P4 & $1 / 102$ & $\mathbf{0}$ & 0.339359 & 0.200804 \\
\hline P8 & $1 / 5$ & $\mathbf{0}$ & 0.051059 & 0.030212 \\
\hline P50 & $1 / 48$ & $\mathbf{0}$ & 0.242303 & 0.143375 \\
\hline P52 & $1 / 16$ & $\mathbf{0}$ & 0.1209 & 0.143375 \\
\hline P60 & $1 / 82$ & $\mathbf{0}$ & 0.313678 & 0.185608 \\
\hline
\end{tabular}

This analysis covers the following quantitative characteristics: abundance, dominance and capacity within each plot. For absolute abundance, more than $76 \%$ of the trees belong to plots 1,4 and 60 . These plots are respectively occupied by $Q$. petraea (151 feet / ha), $S$. japonica (102 feet / ha) and $F$. oregona ( 82 feet / ha). The abundance decreases for other plots and the lowest density is assigned to $\mathrm{P} 8$ (Q. rubra) with 5pieds / ha. The relative abundance follows the same trend as the previous abundance.

High stem density in plots 1, 4 and 50 combined with a reduced diameter (PP, $\mathrm{P}$, and $\mathrm{PB}$ ) allows Arboretum resist wind. Moreover, a relatively large diameter is required to stabilize the stand facing intense height growth resulting from light in competition.

Dominance $(\mathrm{G})$ of all of the arboretum is $16.53 \mathrm{~m}^{2} /$ ha. According to the previously cited formula, $G$ varies depending on the diameter and density of the stand. Thus $Q$. petraea with the maximum value in abundance $(8 \mathrm{~m} /$ ha) in plot $1 . \mathrm{G}$ is very low in P52 ( $F$. americana). The plots 4,8 and 60 have almost the same values. The value of $\mathrm{G}$ in $\mathrm{P} 3$ is almost half of that in P1. The relative dominance is inversely correlated with absolute abundance; it varies from $0.67 \%$ (P1: 151 feet / ha) to 19.85\% (P8: 5 feet / ha).

One hectare of all plots studied provides on average 6.26 $\mathrm{m}^{3}$ / ha of wood.

The graph in Figure 1 evokes the productivity of each wooden piece. Parcel 3 is the richest with a volume of $24.41 \mathrm{~m}^{3}$ / ha. Thus the shape of the figure below is different from the results of analyzes of abundance and dominance. 


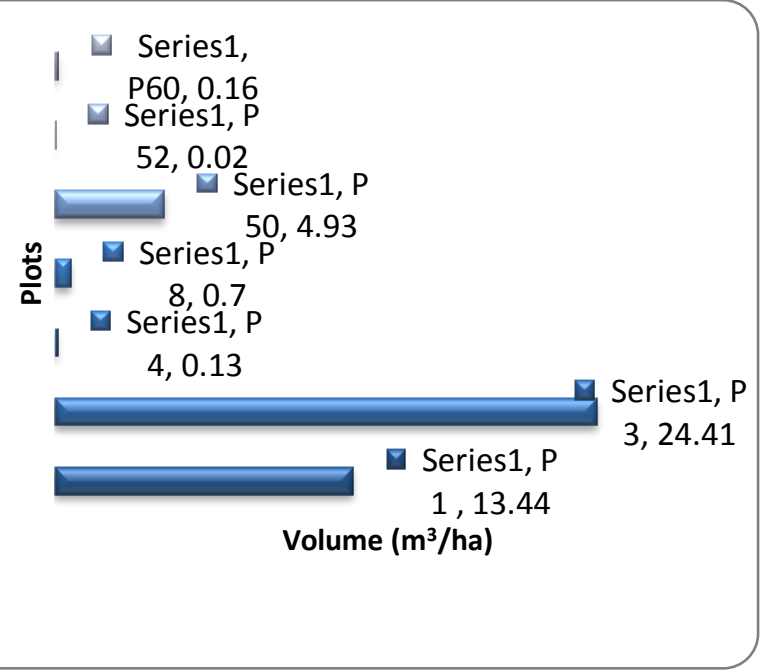

Fig.1. Volume of Wood

The Structure of heights is given by the distribution of the number of stems of all parcels brought hectare for each height class; it provides information on the vertical stratification of the stand.

A large proportion of tree has a height of 2 to $4 \mathrm{~m}$ with 121 pins (stuffed sapling stage), +4 to $8 \mathrm{~m}$ (sapling) with 177 individuals from 10 to $14 \mathrm{~m}$ (low perchis) with 58 stems and finally between 14 to $26 \mathrm{~m}$ (down/up perchis to high forest-grove with 20 or younger individuals. The class of between 2 to $4 \mathrm{~m}$ has a number of significant individuals because of the regeneration is fairly average (Fig. 2).

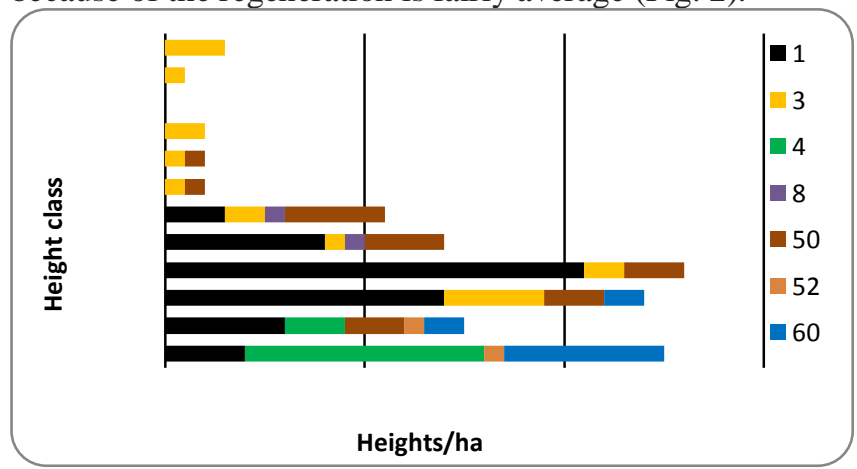

Fig. 2. Distribution of the number of stems per hectare per class height.

\section{CONCLUSION}

This study followed the arboretum's rebuilding momentum through the description of its composition and its wealth of flora and analysis of key species. All this using the full inventory. To do this, seven plots of hardwoods were compared (P1: Quercus petraea, P3: Eucalyptus ovata, P4: Sophora japonica, P8: Quercus rubra, P50: Quercus canariensis, P52: P60 and Fraxinus americana: Fraxinus oregona).

The results showed that the degradation impoverishes the arboretum main species that is to say gasoline's with the minimum diameter of exploitability. At the floristic diversity, 206 individuals belonging to 7 species and 3 families were identified. This is the plot P1 (Quercus petraea), which has the highest rate of absolute and relative abundance, basal area (absolute dominance) respectively with 151 stems / ha, $34.50 \%$ and $8 \mathrm{~m} 2 /$ ha. As for the capacity, the highest value is $24.41 \mathrm{~m} 3$ / ha, it is in the plot 3
(Eucalyptus ovata). Thus, the relatively low rate of diversity indices is explained by the fact that these plots are nonspecific.

\section{REFERENCES}

[1] Hachette L. (1994). Encyclopédie illustré, édition $n^{\circ} 1$ mcp Orléans, France, 2065p.

[2] Andrianandrasana H.T., Randriamahefasoa J., Durbin J., Lewis E.R., Ratsimbazafy J. (2005). Participatory ecological monitoring of the Alaotra wetlands in Madagascar, Biodiversity and Conservation Journal, 2758-74.

[3] Roger Edmond, Rajeriarson C., Rakouth B. (2005). Tohiravina Volume I, Recueil de documents pour suivi écologique du programme environnemental, Faculté des Sciences, 487p.

[4] Pieper Y., Forster H. (1993). Instruction pour l'inventaire de la Station Forestière de Manjakatompo Madagascar, Assistance technique au PDFIV, Deutsche Forst service GmbH, Report DFS 10.4 (DFS / GTZ), 16p.

[5] Rajaonarisoa L. (2002). Contribution à la constitution d.une base de données par l'étude de l'évolution d'occupation des sols entre 1949 et 1996. Cas de la région de Mandraka, Mémoire de fin d'études, Département des Eaux et Forêts ESSA, 101p.

[6] Duplat P., Perrotte G. (1981). Inventaire et Estimation de l'Accroissement des Peuplements Forestiers, Office Nationale des Forêts, Section technique, Paris, 401p.

[7] Dreux P. (1986). Précis d'écologie, Presses Universitaires de France, 281p.

[8] Roger Edmond, Rajeriarson C., Rakouth B. (2007, Tohiravina Volume II, Recueil de documents pour suivi écologique du programme environnemental, Faculté des Sciences, 441p.

[9] Schatz G.E. (2001). Flore Générique des Arbres de Madagascar, Royal Botanic Gardens, Kew \& Missouri Botanical Garden, Edition R. Linklater, 437p.

[10] Bazin P., Barnaud G. (2002). Du suivi à l'évaluation : à la recherche d'indicateurs opérationnels en écologie de la restauration, in www.mnhn.fr, 224p

[11] Sajan R. (2006). Protocole de surveillance de la santé des arbres recommandé par le RESE (Réseau d'Evaluation et de Surveillance Ecologique, Canada). Analyse des données, in www.eman rese.ca/reselecotools/protocols/ errestrial/tree

[12] Hadef A., Rached-Kanouni M. , Alatou D., Toubal O. (2014). Mapping of land by vegetation from Satellite data in the region of Chetaibi (Algeria). International Journal of Management Sciences and Business Research, 3(6), 8-13. 